\title{
Smoking Status and Metabolic Syndrome in the Multi-Ethnic Study of Atherosclerosis. A cross-sectional study
}

\author{
Ivan Berlin ${ }^{1 *}$, Susan Lin ${ }^{2}$, Joao A C Lima ${ }^{3}$ and Alain Gerald Bertoni ${ }^{4}$
}

\begin{abstract}
Background: Current smoking is associated with type 2 diabetes mellitus and impaired glucose tolerance but its association with the metabolic syndrome (metS), particularly with sufficiently sampled African American representation, has not been clearly established.

Objective: To assess whether a) metS is associated with smoking; b) any increased risk of metS among smokers is independent of body mass index (BMI) compared with non-smokers; c) smoking status is differentially associated with the metS and its components across different ethnic groups.

Methods: Cross sectional analysis of the Multi-Ethnic Study of Atherosclerosis (MESA) a community populationbased sample free of cardiovascular disease.

Results: Current smokers $(\mathrm{N}=769)$ had higher risk of metS (odds ratio [OR, 95\% confidence interval]: 1.4, 1.1-1.7) versus never (reference, $\mathrm{N}=2981$ ) and former smokers $(1.0,0.8-1.1, \mathrm{~N}=2163)$ and for metS components: high waist circumference (WC) (OR:1.9, 1.2-2.1), low high density lipoprotein cholesterol (HDL-C) (1.5, 1.3-1.8), elevated plasma triglycerides (TG) (OR:1.4, 1.2-1.7) as well as high C-reactive protein (CRP, an inflammatory marker) concentration (OR: 1.6,1.3-2.0) compared to never and former smokers after adjustment for BMI. A smoking status by ethnicity interaction occurred such that African American current and former smokers had greater likelihood of low HDL-C than White counterparts.

Conclusions: This study found that smoking is associated with the metS and despite the lower BMI of current smokers the prevalence of low HDL-C, elevated TG and CRP is higher among them than among non-smokers. African Americans generally have higher HDL-C than Whites but smoking wipes out this advantage. Multi-Ethnic Study of Atherosclerosis (MESA) ClinicalTrials.gov Identifier: NCT00005487
\end{abstract}

Keywords: Metabolic syndrome, Smoking, Ethnic groups, Body mass index

\section{Introduction}

Tobacco use continues to be the leading global cause of preventable death. It kills nearly 6 million people and causes hundreds of billions of dollars of economic damage worldwide each year [1]. Cigarette smoking causes about 1 of every 5 deaths in the United States each year [2]. The leading causes of death from smoking are cardiovascular diseases (1.69 million deaths), chronic obstructive pulmonary disease ( 0.97 million deaths) and

\footnotetext{
* Correspondence: ivan.berlin@psl.aphp.fr

${ }^{1}$ Hôpital Pitié-Salpêtrière, Assistance publique-Hôpitaux de Paris, Université P.

\& M. Curie, Faculté de médecine, INSERM 894, Paris, France

Full list of author information is available at the end of the article
}

lung cancer (0.85 million deaths) [3]. Smoking cessation leads to reduced mortality, in particular, in patients with coronary heart disease [4]. Active smoking increases the prevalence and incidence of type 2 diabetes mellitus [58] and glucose intolerance [9] as does secondhand smoke exposure $[9,10]$.

Smoking is associated with increased likelihood of low HDL-C [11-13]; and has been suggested to be associated with insulin resistance [14-16] and increased level of inflammatory markers (e.g., CRP) [17,18]. Some studies have assessed the smoking - metS relationship [19-24] but we are not aware of data on the association of smoking status with the clustered metabolic risk factors 
known as metabolic syndrome and its components such as increased TG, reduced HDL-C concentrations, increased blood pressure (BP) and impaired fasting glucose (IFG) in multi-ethnic groups.

It is well known that cigarette smokers weigh less than non-smokers [25-30] and their age and gender adjusted body mass index (BMI) is on average $1 \mathrm{~kg} / \mathrm{m}^{2}$ less than that that of non-smokers [31]. Despite this, compared to non-smokers, current smokers are more likely to have abdominal type obesity $[24,26,29]$. The lower BMI of smokers compared to non-smokers raises questions regarding the impact of smoking on cardiovascular disease (CVD) risk factors such as the metS, its components and inflammatory markers such as CRP [32].

Therefore the aims of this cross sectional analysis were a) to assess metabolic syndrome, its components and a CVD risk factor CRP among smokers compared to former and never smokers; b) to test the contribution of BMI on the associations between smoking status and these risk factors; and c) to evaluate whether the association of smoking status with these risk factors varies across ethnicity and secondarily by gender.

\section{Methods}

\section{Study population}

The Multi-Ethnic Study of Atherosclerosis (MESA) is a multicenter cohort study of participants recruited between 2000 and 2002; details regarding recruitment and design have previously been published [33]. Briefly, it is a population-based sample of men and women aged 4584 who identified themselves as non-Hispanic White, African-American, Hispanic or Chinese American and were free of clinically apparent cardiovascular disease. Participants were recruited from six US communities: Baltimore City and County, MD, Chicago, Ill, Forsyth County, NC, Los Angeles County, CA, northern Manhattan and the Bronx, NY, and St Paul, MN. The institutional review boards of all participating centers approved the study and all participants gave informed consent. From the total sample $(\mathrm{N}=6814)$ we excluded participants with missing smoking status or missing other data precluding the characterization of metabolic syndrome. We excluded participants with diabetes, or taking medicines for diabetes or having fasting glucose $>125 \mathrm{mg} / \mathrm{dL}$, and those whose diabetes status was unknown. Thus, the study population consisted of 5913 participants: 37.6\% non-Hispanic Whites, 23.6\% African Americans, 10.7\% Chinese Americans and 28.1\% Hispanics.

\section{Measures}

At baseline, questionnaires were used to obtain information about demographics, socioeconomic status, medical history and medications. Waist circumference at the umbilicus was measured to the nearest $0.1 \mathrm{~cm}$ using a steel measuring tape. Height and weight was measured by a stadiometer and calibrated scale. Body mass index was calculated from height and weight as $\mathrm{kg} / \mathrm{m}^{2}$. Resting blood pressure was measured three times with participants in a seated position with a Dinamap model Pro100 automated oscillometric sphygmomanometer (Critikon); the average of the last two measurements was used in the analysis. Triglycerides, HDL-C, blood glucose, and plasma insulin concentrations were measured from blood samples obtained after a 12-hour fast. Metabolic syndrome was classified using the updated Adult Treatment Panel III (ATP III) definition [34] as three or more of the following: High WC (WC $>102 \mathrm{~cm}$ for men and WC $>88 \mathrm{~cm}$ for women); elevated TG $(\geq 150 \mathrm{mg} / \mathrm{dL})$; low HDL-C (men $<40$ and women $<50 \mathrm{mg} / \mathrm{dL}$ ); elevated blood pressure (systolic blood pressure $\geq 130$ or diastolic blood pressure $\geq 85 \mathrm{mmHg}$ or use of medications for hypertension); and elevated fasting glucose $(\geq 100 \mathrm{mg} / \mathrm{dL})$. For Chinese Americans we used the International Diabetes Federation (IDF) cut off point for high WC: $>90 \mathrm{~cm}$ for men and $>80 \mathrm{~cm}$ for women [35]. We defined impaired fasting glucose as between $100 \mathrm{mg} / \mathrm{dL}$ and125 mg/dL. Insulin resistance was estimated by homeostasis model assessment of insulin resistance (HOMA-IR), calculated according to the formula (insulin $(\mathrm{mU} / \mathrm{I}) *($ glucose $[\mathrm{mg} / \mathrm{dL}] 0.055) / 22.5)$. The top quartile value was used as cutoff point to determine insulin resistance. CRP was measured using the BNII nephelometer (N High-Sensitivity CRP); intra-assay coefficient of variation for CRP range from 2.3 to $4.4 \%$ and inter-assay coefficients of variation range from 2.1 to $5.7 \%$ [36]. Elevated CRP was defined as CRP $\geq 5 \mathrm{mg} / \mathrm{L}$ [37]. Physical activity was measured by using a detailed, semiquantitative questionnaire adapted from the CrossCultural Activity Participation Study [38]. The sum of minutes spent in all activity types was multiplied by the metabolic equivalent (MET) level and physical activity level was expressed as min/week*MET [39].

Never smoking was defined as lifetime consumption of less than 100 cigarettes $(\mathrm{N}=2981)$. There were 2163 former smokers. Among them, 2105 quit smoking $\geq 1$ year earlier and 58 between 30 days and 1 year. These latter were added to the group of former smokers. The mean pack years was $21(\mathrm{SD}=25)$ for former and 27 $(\mathrm{SD}=32)$ for current smokers. Data were analyzed according to smoking status and not according to pack years for two reasons. First, use of pack years does not provide information about former smoking status and can erase the effect of quitting. Second, a body of tobacco research has suggested that smoking induced disease risk, in particular cardiovascular risk, is dependent to a greater degree on the duration of exposure, and less dependent on the amount smoked (i.e. low number of cigarettes per day or occasional cigarette 
smoking can also be associated with increased disease risk) [40].

Alcohol use was screened with the following questions: "Have you ever consumed alcoholic beverages?" and "Do you presently drink alcoholic beverages?" and participants were classified as current, former or never users.

\section{Data analysis}

ANOVA and chi-square tests were used to examine the characteristics of the study participants by smoking status (never, former and current smoker). Logistic regression models were used to examine the association of smoking status with CVD risk factors with and without adjustment for BMI. The following factors were included as covariates: age, gender, ethnicity, site, household income, alcohol consumption, physical activity, lipid lowering and antihypertensive drugs and education. Interactions of race/ethnicity and gender with smoking status were tested for each CVD risk factor. Data are reported as frequencies and odds ratios (OR) with 95\% confidence intervals $(\mathrm{CI})$ if otherwise not indicated. Significance level was set at $\mathrm{p} \leq 0.05$.

\section{Results}

Current smokers were younger, and reported less household income and education than never smokers. Current smoking was the most frequent among non-Hispanic Whites and the less frequent among Chinese Americans. Use of antihypertensive medications or lipid lowering drugs were less frequent among current smokers than among never or former smokers and they reported more moderate/vigorous physical activity.

The prevalence of ATP-III metS was similar between the three smoking status groups. However, when looking at the individual metS components, the prevalence of all risk factors except IFG and HOMA-IR were significantly different between smokers, former smokers and never smokers. In particular, while among current smokers high WC, above normal BMI (overweight/obesity), and elevated BP were less frequent, current smokers had higher prevalence of low HDL-C, high plasma TG and elevated CRP (Table 1).

Table 2 shows the associations of smoking status with metS and its components with and without adjustment for BMI. Smoking status was significantly associated with the presence of metS or high WC only in the models adjusted for BMI. Without adjustment for BMI, HOMA-IR was significantly less frequent among current smokers than among former or never smokers but the differences disappeared after adjustment for BMI (Table 2).

The significant association of low HDL-C, elevated TG and elevated CRP with smoking status did not change after adjusting for BMI (Table 2).
Table 3 shows the significant interactions of smoking status with ethnicity and gender. There was a significant interaction of smoking status with ethnic groups for HDL-C. Among African Americans both former and current smokers were more likely than never smokers to have low HDL-C while only current smokers were more likely to have low HDL-C among non-Hispanic Whites or Hispanics. Thus, the significant smoking status by ethnicity interaction results from the higher likelihood to have a higher prevalence of low-HDL-C among former smoker African Americans than among nonHispanic Whites or Hispanics.

There was no statistically significant difference in elevated TG or high WC by smoking status neither among males nor among females. However, when adjustment was made for BMI, male current and former smokers were more likely to have high WC than never smokers. These associations were not statistically significant among females.

\section{Discussion}

This study found that current smoking is associated with the metS and despite the lower BMI of current smokers the prevalence of high WC, low HDL-C, elevated TG is higher than among non-smokers. The prevalence of high CRP, an inflammatory marker associated with CVD risk [32] was also higher among current smokers compared to never or former smokers. The only difference which occurred between smokers of different ethnic origin concerned low HDL-C: the highest risk for low HDL-C was observed among African American current and former smokers.

At any age, both male and female smokers have lower BMI than non-smokers or former smokers $[25,27,28,30]$. Thus the question arises whether BMI influences or not the presence of metS and its components among persons of different smoking status: never, former or current smoking. When adjusted for BMI, we found that smokers were at higher risk of metS and high WC. Although smokers of this sample seemed to have less frequently insulin resistance than non-smokers (never or former smokers), this apparent benefit was simply related to the confounding effect of their lower BMI. Although adjustment for BMI had no influence on the prevalence of elevated blood pressure and impaired fasting glucose concentration, it revealed that the metS is more frequent among current than among former or never smokers, and that the high WC is associated with current smoking. Smoking seems to be associated with low HDL-C, high TG and CRP independently of BMI.

Conflicting data exist about the smoking status - metS relationship. Data from the Third National Health and Nutrition Examination Survey (NHANES III) showed that when adjusted for all modifiable lifestyle factors 
Table 1 Characteristics of the study population by smoking status

\begin{tabular}{|c|c|c|c|c|}
\hline & Never smoker & Former smoker & Current smoker & P-value \\
\hline & $\mathrm{N}=\mathbf{2 9 8 1}$ & $\bar{N}=2163$ & $\mathrm{~N}=769$ & \\
\hline \multicolumn{5}{|l|}{ Demographics } \\
\hline Age (years) & $61.8(10.6)$ & $63.2(9.9)$ & $57.8(9.2)$ & $<0.001$ \\
\hline Gender-Males (\%) & 37.7 & 56.9 & 50.8 & $<0.002$ \\
\hline Race/ethnicity (\%) & & & & $<0.001$ \\
\hline Non-Hispanic White & 36.4 & 50.0 & 36.8 & \\
\hline Chinese American & 17.7 & 6.1 & 4.7 & \\
\hline African American & 23.3 & 26.1 & 36.3 & \\
\hline Hispanic & 22.5 & 17.9 & 22.2 & \\
\hline Education (\%) & & & & $<0.001$ \\
\hline High school or less & 36.5 & 29.9 & 38 & \\
\hline Some college & 24.8 & 30.8 & 37.8 & \\
\hline Bachelor or graduate & 38.7 & 39.3 & 24.2 & \\
\hline Household income level per year (\%) & & & & $<0.001$ \\
\hline$<\$ 25000$ & 31.9 & 26.0 & 31.5 & \\
\hline$>\$ 25000$ and $<\$ 50000$ & 28.2 & 27.7 & 32.8 & \\
\hline$>\$ 50000$ and $<\$ 75000$ & 16.4 & 18.6 & 18.4 & \\
\hline$>\$ 75000$ & 23.4 & 27.7 & 17.3 & \\
\hline \multicolumn{5}{|l|}{ Medications } \\
\hline Use of antihypertensive medications (\%) & 30.7 & 30.4 & 23.4 & $<0.001$ \\
\hline Use of lipid lowering medications (\%) & 14.1 & 16.3 & 10.7 & $<0.001$ \\
\hline \multicolumn{5}{|l|}{ Behavioral variables } \\
\hline Alcohol use (\%) & & & & $<0.001$ \\
\hline Never & 32.4 & 6.2 & 8.2 & \\
\hline Former & 18.2 & 28.4 & 22.5 & \\
\hline Current & 49.4 & 65.4 & 69.3 & \\
\hline Physical activity (min/week-MET) & $5604(5625)$ & $5857(6095)$ & $6631(6662)$ & $<0.001$ \\
\hline First quartile $<2055$ & 26.0 & 23.2 & 25.6 & $<0.001$ \\
\hline 2nd quartle (2055-4125) & 25.4 & 26.8 & 19.0 & \\
\hline 3rd quartile (4125-7545) & 24.8 & 25.7 & 23.9 & \\
\hline 4th quartile (>7545) & 23.8 & 24.3 & 31.5 & \\
\hline \multicolumn{5}{|l|}{ Cardiometabolic profile (\%) } \\
\hline ATP-III Metabolic syndrome & 26.5 & 26.3 & 27.3 & 0.9 \\
\hline \multicolumn{5}{|l|}{ Metabolic syndrome components } \\
\hline High WC & 58.2 & 53.5 & 51.6 & $<0.001$ \\
\hline Elevated BP & 50.9 & 54.8 & 44.0 & $<0.001$ \\
\hline Low HDL-C & 34.1 & 31.4 & 42.0 & $<0.001$ \\
\hline Elevated TG & 27.6 & 26.1 & 32.3 & 0.005 \\
\hline Impaired fasting glucose & 15.7 & 16.3 & 14.7 & 0.6 \\
\hline Insulinresistance (HOMA-IR) & 25.5 & 26.6 & 23.6 & 0.3 \\
\hline Elevated CRP & 18.1 & 19.5 & 24.0 & 0.001 \\
\hline Normal weight (BMl < 25) & 32.7 & 27.3 & 30.9 & $<0.001$ \\
\hline Obese (BMI > 29.9) & 29.0 & 31.6 & 28.2 & 0.08 \\
\hline
\end{tabular}

Data are means (SD) or percentages. 
Table 2 Effect of body mass index (BMI) on the association of cardiovascular disease risk factors with smoking status

\begin{tabular}{|c|c|c|c|c|c|c|c|c|}
\hline & \multicolumn{3}{|c|}{ BMI unadjusted OR } & \multirow[t]{2}{*}{ p-value } & \multicolumn{3}{|c|}{ BMI adjusted OR } & \multirow[t]{2}{*}{ p-value } \\
\hline & $\begin{array}{l}\begin{array}{l}\text { Never } \\
\text { smokers }\end{array} \\
\end{array}$ & $\begin{array}{l}\begin{array}{l}\text { Former } \\
\text { smokers }\end{array} \\
\end{array}$ & $\begin{array}{l}\text { Current } \\
\text { smokers }\end{array}$ & & $\begin{array}{l}\begin{array}{l}\text { Never } \\
\text { smokers }\end{array} \\
\end{array}$ & $\begin{array}{l}\text { Former } \\
\text { smokers }\end{array}$ & $\begin{array}{l}\text { Current } \\
\text { smokers }\end{array}$ & \\
\hline Metabolic syndrome & reference & $1.0(0.9-1.2)$ & $1.1(.9-1.3)$ & 0.5 & reference & $1.0(0.8-1.1)$ & $1.4(1.1-1.7)$ & 0.03 \\
\hline \multicolumn{9}{|l|}{ Metabolic syndrome components } \\
\hline High WC & reference & $1.1(0.9-1.2)$ & $0.9(0.7-1.1)$ & 0.2 & reference & $1.1(0.9-1.3)$ & $1.6(1.2-2.1)$ & 0.004 \\
\hline Elevated BP & reference & $1.1(0.9-1.2)$ & $0.9(0.7-1.0)$ & 0.09 & reference & $1.0(0.9-1.2)$ & $0.9(0.8-1.1)$ & 0.5 \\
\hline Low HDL-C & reference & $1.0(0.9-1.1)$ & $1.3(1.2-1.6)$ & 0.001 & reference & $1.0(0.8-1.1)$ & $1.5(1.3-1.8)$ & $<0.001$ \\
\hline Elevated TG & reference & $1.0(0.9-1.1)$ & $1.1(1.1-1.6)$ & 0.009 & reference & $1.0(0.8-1.1)$ & $1.4(1.2-1.7)$ & $<0.001$ \\
\hline Impaired fasting glucose & reference & $1.0(0.8-1.1)$ & $1(0.8-1.2)$ & 0.9 & reference & $0.9(0.8-1.1)$ & $1.1(0.9-1.4)$ & 0.2 \\
\hline Insulin resistance (HOMA-IR) & reference & $1.1(0.9-1.2)$ & $0.8(0.7-0.98)$ & 0.02 & reference & $1(0.9-1.2)$ & $1.0(0.8-1.2)$ & 0.9 \\
\hline Elevated CRP & reference & $1.2(1.03-1.4)$ & $1.3(1.1-1.6)$ & 0.01 & reference & $1.2(0.98-1.4)$ & $1.6(1.3-2.0)$ & $<0.001$ \\
\hline
\end{tabular}

Adjusted for age, gender, ethnicity, site, household income, alcohol consumption, physical activity, lipid lowering and antihypertensive drug and education. OR are shown with one decimal for clarity.

Data are odds ratios (OR) and (95\% confidence intervals).

current smoking, when compared to never smoking, was associated with increased risk of metS when adjusted for BMI for both men and women [19]. In a Korean population, more than 20 pack-year smoking has been found to be associated with a 1.9 fold risk of BMI adjusted metS [20]. A recent cross sectional study did not find an association between smoking status and metS [21] but no adjustment was made for BMI. Geslain-Biquez et al. [22] reported that the frequency of metS was higher among smokers $(22.5 \%)$ than among non-smokers (15.3\%). In this sample there was no difference in BMI between smokers and non-smokers showing that at equal BMI smoking is associated with increased prevalence of metS. To our knowledge only two prospective studies reported about incident metS and smoking status. Carnethon et al. [23] found when analyzing data of the CARDIA study that baseline smoking status did not predict incident metS during an average follow up of 13.6 years but there is no information what was the percent of smokers who became former smokers which potentially could

Table 3 Differential association of metabolic syndrome components with smoking status by gender and race

\begin{tabular}{|c|c|c|c|c|c|c|c|c|}
\hline & \multicolumn{3}{|c|}{ BMI unadjusted OR } & \multirow[t]{2}{*}{ p-value } & \multicolumn{3}{|c|}{ BMI adjusted OR } & \multirow[t]{2}{*}{ p-value } \\
\hline & $\begin{array}{l}\text { Never } \\
\text { smokers }\end{array}$ & $\begin{array}{l}\text { Former } \\
\text { smokers }\end{array}$ & $\begin{array}{l}\text { Current } \\
\text { smokers }\end{array}$ & & $\begin{array}{l}\text { Never } \\
\text { smokers }\end{array}$ & $\begin{array}{l}\text { Former } \\
\text { smokers }\end{array}$ & $\begin{array}{l}\text { Current } \\
\text { smokers }\end{array}$ & \\
\hline \multicolumn{9}{|l|}{ Elevated TG* } \\
\hline Males & reference & $1.0(0.8-1.3)$ & $1.4(1.1-1.8)$ & 0.055 & reference & $1.0(0.8-1.2)$ & $1.5(1.1-2.0)$ & 0.006 \\
\hline Females & reference & $1.0(0.8-1.2)$ & $1.3(0.9-1.7)$ & 0.3 & reference & $1.0(0.8-1.2)$ & $1.4(0.99-1.8)$ & 0.06 \\
\hline Interaction of gender with smoking status & & & & 0.02 & & & & 0.04 \\
\hline \multicolumn{9}{|l|}{ High WC* } \\
\hline Males & reference & $1.2(1.0-1.5)$ & $1.1(0.9-1.4)$ & 0.1 & reference & $1.3(1.0-1.7)$ & $2.2(1.5-3.3)$ & $<0.001$ \\
\hline Females & reference & $1.0(0.9-1.3)$ & $0.8(0.6-1.0)$ & 0.08 & reference & $1.0(0.8-1.3)$ & $1.2(0.8-1.8)$ & 0.7 \\
\hline Interaction of gender with smoking status & & & & $<0.001$ & & & & $<0.001$ \\
\hline \multicolumn{9}{|l|}{ Low HDL-C** } \\
\hline Non-Hispanic Whites & reference & $0.8(0.7-1.0)$ & $1.3(1.0-1.7)$ & 0.02 & reference & $0.9(0.7-1.0)$ & $1.5(1.1-2.0)$ & 0.001 \\
\hline African Americans & reference & $1.5(1.1-1.9)$ & $1.6(1.1-2.2)$ & 0.007 & reference & $1.4(1.1-1.9)$ & $1.8(1.3-2.6)$ & 0.001 \\
\hline Hispanics & reference & $1.1(0.8-1.5)$ & $1.5(1.0-2.2)$ & 0.01 & reference & $1.1(0.8-1.4)$ & $1.6(1.1-2.3)$ & 0.07 \\
\hline Chinese Americans & reference & $0.7(0.4-1.2)$ & $1.2(0.6-2.5)$ & 0.3 & reference & $0.7(0.4-1.1)$ & $1.1(0.5-2.3)$ & 0.3 \\
\hline Interaction of ethnicity with smoking status & & & 0.056 & & & & & 0.026 \\
\hline
\end{tabular}

*Adjusted for age, ethnicity, site, household income, alcohol consumption, physical activity, lipid lowering and antihypertensive drug and education. ${ }^{*}$ Adjusted for age, gender, site, household income, alcohol consumption, physical activity, lipid lowering and antihypertensive drug and education. OR are shown with one decimal for clarity.

Data are odds ratios (OR) and (95\% confidence intervals). 
reduce the risk of developing metS. Although this study demonstrated ethnic differences in developing metS, it did not report on ethnicity by smoking status interaction [23]. In a Turkish population during a mean follow up of 5.9 years smoking was inversely associated with WC and among women smoking reduced the risk of metS by half; however this "protective" effect of smoking on metS was not accompanied by a subsequent reduction in coronary heart disease or all-cause mortality [24].

In the current sample the multivariate analysis showed that smoking status was not associated with blood pressure. The relationship between smoking and blood pressure is controversial some studies reporting higher others lower blood pressure [41]. However, compared to non-smokers, smoking has been more consistently found to be associated with lower systolic and diastolic blood pressure in Nord-American [17], European [24,42] and Asian populations $[43,44]$. The lower blood pressure found among smokers may be associated with their lower BMI as shown in the present study.

In the present study we did not find in the multivariate analysis that HOMA IR, a proxy measure of insulin resistance, or fasting plasma glucose concentration were associated with smoking status. It has been suggested that the insulin resistance syndrome is the key player between cigarette smoking and CVD [15]. This hypothesis is mainly based on acute human lab studies $[14,16]$ and on the considerations that smoking may result in reduced skeletal muscular blood flow, vascular changes and abdominal type adiposity, all potentially associated with reduced insulin-mediated glucose uptake and insulin sensitivity. However, a large cross sectional study did not confirm that active smoking was associated with increased insulin resistance [45]. Further studies are needed to explore specifically the smoking - insulin resistance relationship.

Because of the demonstrated ethnic and gender differences in the prevalence of the metS and its components [46-50], this study tested whether the association of the metS and its components with smoking varied by ethnicity and secondarily by gender. There was no apparent evidence that the studied CVD risk factors associated with smoking varied significantly by ethnic groups except the finding that low HDL-C was more prevalent among African American current and former smokers compared with non-smokers and their counterparts in other ethnic groups. African Americans generally have higher HDL-C than non-Hispanic Whites. According to the present data smoking is associated with reduction in (the protective) HDL-C in African Americans and may increase by this their CVD risk more than among nonHispanic Whites. This finding strongly suggests that intensive specific interventions should be targeted among African American smokers and former smokers to improve their smoking induced negative lipid profile to reduce the burden of CVD risk.

The prevalence of metS components and CRP did not differ between males and females according to smoking status suggesting a similar risk factor level among men and women smokers. The unfavourable association of current and former smoking with high WC after adjustment for BMI became significant only among males. It is not clear whether this differential association with gender concerning only WC was related to the intensity of exposure to tobacco or to other factors. Future studies are needed to examine the plausible causes.

There are several limitations to this study. This was a cross sectional analysis; smoking status was based on self-report and no biological validation approaches such as expired air carbon monoxide or saliva/plasma/urine cotinine concentrations were used to confirm self-report of smoking status. BMI is inversely related with the number of cigarettes smoked per day [26]. It has also been shown that HDL-C levels decrease on a dosedependent way with increases in the number of cigarettes smoked per day [11]. It would have been important to analyze if, among current smokers, these dose-response relationships exist for other metS components and whether they are similar or not across the different ethnic groups or gender. Unfortunately, this could not have been done because of the low power for these analyses: among current smokers cigarettes per day categories by ethnic groups or by gender yielded very few cell numbers. A major limitation is that the cross sectional nature of the data did not allow assessing prospectively changes in metS and its components in particular among smokers who quit.

Because smokers cite control of body weight as a reason to continue smoking [51-55] and the tobacco industry reinforces this notion through advertising [56] it is important to look at the effect of the lower body weight associated with current smoking on CVD risk factors such as metS components and inflammatory markers. This study found that lower BMI of current smokers does not improve their lipid profile and the inflammatory marker CRP. This can partially explain that lower BMI of smokers does not protect against developing smoking related cardiovascular disorders.

In conclusion, smoking is associated with the metS and despite the lower BMI of smokers compared to non-smokers the risk profile of components of metS with demonstrated association with CVD risk is maintained. Among African Americans who generally have higher HDL-C than Whites, smoking nullifies this advantage. Current smoking may differentially be associated with metS components in specific ethnic groups or among males potentially leading to a differentially increased CVD risk. 


\section{Competing interests}

Author Disclosure Statement: None of the authors reports competing financial interest in connection with this manuscript. I. Berlin has a tenureship salary from Université P.\& M. Curie and Assistance publiqueHôpitaux de Paris. He had no any other funding source supporting this work. He reports having received honoraria for consultancies over the past 5 years from Sanofi-Aventis and Pfizer Ltd. without any relationship with this manuscript. Susan Lin, Joao Lima and Alain G. Bertoni report no conflict of interest. None of the authors declare any non-financial competing interests. All authors declare not having any kind of relationship with the tobacco or alcohol industry.

\section{Authors' contributions}

$\mathrm{IB}$ and $\mathrm{SL}$ conceived and drafted the first version of the manuscript. IB, SL and $A B$ drafted the statistical analytical plan. IB and SL analyzed the data. JL participated in the design of the study and helped to draft the manuscript. All authors read and approved the final manuscript.

\section{Acknowledgments}

The authors thank the other investigators, the staff, and the participants of the MESA study for their valuable contributions. A full list of participating MESA investigators and institutions can be found at http://www.mesa-nhlbi. org.The MESA study was supported by contracts N01-HC-95159 through N01-HC-95169 from the National Heart, Lung and Blood Institute.

\section{Author details}

'Hôpital Pitié-Salpêtrière, Assistance publique-Hôpitaux de Paris, Université P. \& M. Curie, Faculté de médecine, INSERM 894, Paris, France. ${ }^{2}$ Center for Family and Community Medicine, Columbia University, New York, NY, USA. ${ }^{3}$ Johns Hopkins University School of Medicine, Baltimore, MD, USA. ${ }^{4}$ Wake Forest University School of Medicine, Winston-Salem, NC, USA.

Received: 30 March 2012 Accepted: 9 June 2012

Published: 20 June 2012

\section{References}

1. WHO Report on the Global Tobacco Epidemic: Warning about the dangers of tobacco. 2012. http://whqlibdoc.who.int/hq/2011/ WHO_NMH_TFI_11.3_eng.pdf. Accessed on Jan 19, 2012.

2. Center for Disease Control: Smoking \& Tobacco Use - Tobacco related mortality. 2012. http://www.cdc.gov/tobacco/data_statistics/fact_sheets/ health_effects/tobacco_related_mortality/Accessed on Jan 19, 2012.

3. Ezzati $\bar{M}$, Lopez AD: Estimates of global mortality attributable to smoking in 2000. Lancet 2003, 362(9387):847-852.

4. Critchley J, Capewell S: Smoking cessation for the secondary prevention of coronary heart disease. Cochrane Database Syst Rev 2004, 1:CD003041.

5. Berlin I: Smoking-induced metabolic disorders: a review. Diabetes Metab 2008, 34:307-314

6. Willi C, Bodenmann P, Ghali WA, Faris PD, Cornuz J: Active smoking and the risk of type 2 diabetes: a systematic review and meta-analysis. JAMA 2007, 298:2654-2664.

7. Yeh HC, Duncan BB, Schmidt MI, Wang NY, Brancati FL: Smoking, smoking cessation, and risk for type 2 diabetes mellitus: a cohort study. Ann Intern Med 2010, 152:10-17.

8. Luo J, Rossouw J, Tong E, Giovino GA, Lee C, Chen C, Ockene JK, Qi L, Margolis KL: Smoking cessation, weight gain, and risk of type 2 diabetes mellitus among postmenopausal women. Arch Intern Med 2012, 172:438-440.

9. Houston TK, Person SD, Pletcher MJ, Liu K, Iribarren C, Kiefe Cl: Active and passive smoking and development of glucose intolerance among young adults in a prospective cohort: CARDIA study. BMJ 2006, 332:1064-1069.

10. Kowall B, Rathmann W, Strassburger K, Heier M, Holle R, Thorand B, Giani G, Peters A, Meisinger C: Association of passive and active smoking with incident type 2 diabetes mellitus in the elderly population: the KORA S4/ F4 cohort study. Eur J Epidemiol 2010, 25:393-402.

11. Craig WY, Palomaki GE, Haddow JE: Cigarette smoking and serum lipid and lipoprotein concentrations: an analysis of published data. BMJ. 1989, 298:784-788.

12. Bakhru A, Erlinger TP: Smoking cessation and cardiovascular disease risk factors: results from the Third National Health and Nutrition Examination Survey. PLoS Med 2005, 2(6):e160.
13. Rouvre M, Vol S, Gusto G, et al: Low high density lipoprotein cholesterol: prevalence and associated risk-factors in a large French population. Ann Epidemiol 2010, 21:118-127.

14. Attvall S, Fowelin J, Lager I, Von Schenck H, Smith U: Smoking induces insulin resistance-a potential link with the insulin resistance syndrome. $J$ Intern Med 1993, 233:327-332.

15. Reaven G, Tsao PS: Insulin resistance and compensatory hyperinsulinemia: the key player between cigarette smoking and cardiovascular disease? J Am Coll Cardiol 2003, 41:1044-1047.

16. Borissova AM, Tankova T, Kirilov G, Dakovska L, Krivoshiev S: The effect of smoking on peripheral insulin sensitivity and plasma endothelin level. Diabetes Metab 2004, 30:147-152.

17. Bazzano LA, He J, Muntner P, Vupputuri S, Whelton PK: Relationship between cigarette smoking and novel risk factors for cardiovascular disease in the United States. Ann Intern Med 2003, 138:891-897.

18. Tonstad S, Cowan JL: C-reactive protein as a predictor of disease in smokers and former smokers: a review. Int J Clin Pract 2009, 63:1634-1641.

19. Zhu S, St-Onge MP, Heshka S, Heymsfield SB: Lifestyle behaviors associated with lower risk of having the metabolic syndrome. Metabolism 2004, 53:1503-1511.

20. Lee WY, Jung CH, Park JS, Rhee EJ, Kim SW: Effects of smoking, alcohol, exercise, education, and family history on the metabolic syndrome as defined by the ATP III. Diabetes Res Clin Pract 2005, 67:70-77.

21. Katano S, Nakamura Y, Nakamura A, et al: Relationship among physical activity, smoking, drinking and clustering of the metabolic syndrome diagnostic components. J Atheroscler Thromb 2010, 17:644-650.

22. Geslain-Biquez C, Vol S, Tichet J, Caradec A, D'Hour A, Balkau B: The metabolic syndrome in smokers. The D.E.S.I.R. study. Diabetes Metab 2003, 29:226-234

23. Carnethon MR, Loria CM, Hill JO, Sidney S, Savage PJ, Liu K: Risk factors for the metabolic syndrome: the Coronary Artery Risk Development in Young Adults (CARDIA) study, 1985-2001. Diabetes Care 2004, 27:2707-2715.

24. Onat A, Ozhan H, Esen AM, et al: Prospective epidemiologic evidence of a "protective" effect of smoking on metabolic syndrome and diabetes among Turkish women-without associated overall health benefit. Atherosclerosis 2007, 193:380-388.

25. Williamson DF, Madans J, Anda RF, Kleinman JC, Giovino GA, Byers T: Smoking cessation and severity of weight gain in a national cohort. $N$ Engl J Med 1991, 324:739-745.

26. Shimokata $H$, Muller DC, Andres R: Studies in the distribution of body fat III. Effects of cigarette smoking. JAMA 1989, 261:1169-1173.

27. Molarius A, Seidell JC, Kuulasmaa K, Dobson AJ, Sans S: Smoking and relative body weight: an international perspective from the $\mathrm{WHO}$ MONICA Project. J Epidemiol Community Health 1997, 51:252-260.

28. Albanes D, Jones DY, Micozzi MS, Mattson ME: Associations between smoking and body weight in the US population: analysis of NHANES II. Am J Public Health 1987, 77:439-444.

29. Chiolero A, Faeh D, Paccaud F, Cornuz J: Consequences of smoking for body weight, body fat distribution, and insulin resistance. Am J Clin Nutr 2008, 87:801-809.

30. Canoy D, Wareham $N$, Luben $R$, et al: Cigarette smoking and fat distribution in 21,828 British men and women: a population-based study. Obes Res 2005, 13:1466-1475.

31. Bamia C, Trichopoulou A, Lenas D, Trichopoulos D: Tobacco smoking in relation to body fat mass and distribution in a general population sample. Int J Obes Relat Metab Disord 2004, 28:1091-1096.

32. The Emerging Risk Factors Collaboration: C-reactive protein concentration and risk of coronary heart disease, stroke, and mortality: an individual participant metaanalysis. Lancet 2010, 375:132-140.

33. Bild DE, Bluemke DA, Burke GL, et al: Multi-ethnic study of atherosclerosis: objectives and design. Am J Epidemiol 2002, 156:871-881.

34. Grundy SM, Brewer HB Jr, Cleeman Jl, Smith SC Jr, Lenfant C: Definition of metabolic syndrome: report of the National Heart, Lung, and Blood Institute/American Heart Association conference on scientific issues related to definition. Arterioscler Thromb Vasc Biol 2004, 24:e13-e18.

35. Alberti KG, Zimmet P, Shaw J: Metabolic syndrome-a new world-wide definition. A Consensus Statement from the International Diabetes Federation. Diabet Med 2006, 23:469-480.

36. Bertoni $A G$, Burke $G L$, Owusu JA, et al: Inflammation and the incidence of type 2 diabetes: the Multi-Ethnic Study of Atherosclerosis (MESA). Diabetes Care 2010, 33:804-810. 
37. Bahrami H, Bluemke DA, Kronmal R, et al: Novel metabolic risk factors for incident heart failure and their relationship with obesity: the MESA (Multi-Ethnic Study of Atherosclerosis) study. J Am Coll Cardiol 2008, 51:1775-1783.

38. Ainsworth BE, Haskell WL, Whitt MC, et al: Compendium of physical activities: an update of activity codes and MET intensities. Med Sci Sports Exerc 2000, 32:S498-S504.

39. Bertoni $A G$, Whitt-Glover MC, Chung $H$, et al: The association between physical activity and subclinical atherosclerosis: the Multi-Ethnic Study of Atherosclerosis. Am J Epidemiol 2009, 169:444-454.

40. Fiore MC, Baker TB: Treating smokers in the health care setting. N Eng/ J Med 2011, 365:1222-1231.

41. Leone A: Does smoking act as a friend or enemy of blood pressure? Let release Pandora's box. Cardiol Res Pract 2011, 264894.

42. Barnaards CM, Twisk JWR, Snel J, van Mechelen W, Kemper HCG: In a prospective study in young people, associations between changes in smoking behavior and risk for cardiovascular dieseas were complex. $J$ Clin Epidemiol 2005, 58:1165-1171.

43. Teshima K, Imamura H, Uchida K, Miyamoto N, Masuda Y, Kobata D: Cigarette smoking, blood pressure and serum lipids in Japanese men aged 20-39 years. J Physiol Anthropol Appl Human Sci 2001, 20:43-45.

44. Imamura H, Teshima K, Miyamoto N, Shirota T: Cigarette smoking, highdensity lipoprotein cholesterol subfractions, and lecithin: cholesterol acyltransferase in young women. Metabolism 2002, 51:1313-1316.

45. Henkin L, Zaccaro D, Haffner S, Karter A, Rewers M, Sholinsky P, Wagenknecht L: Cigarette smoking, environmental tobacco smoke exposure and insulin sensitivity. Ann Epidemiol 1999, 9:290-296.

46. Lin SX, Carnethon M, Szklo M, Bertoni A: Racial/ethnic differences in the association of triglycerides with other metabolic syndrome components: the Multi-Ethnic Study of Atherosclerosis. Metab Syndr Relat Disord 2010, 9:35-40.

47. Metcalf PA, Sharrett AR, Folsom AR, et al: African American-white differences in lipids, lipoproteins, and apolipoproteins, by educational attainment, among middle-aged adults: the Atherosclerosis Risk in Communities Study. Am J Epidemiol 1998, 148:750-760.

48. Cowie CC, Howard BV, Harris Ml: Serum lipoproteins in African Americans and whites with non-insulin-dependent diabetes in the US population. Circulation 1994, 90:1185-1193.

49. Morrison JA, Khoury P, Mellies M, Kelly K, Horvitz R, Glueck CJ: Lipid and lipoprotein distributions in black adults. The Cincinnati Lipid Research Clinic's Princeton School Study. JAMA 1981, 245:939-942.

50. Carnethon MR, Palaniappan LP, Burchfiel CM, Brancati FL, Fortmann SP: Serum insulin, obesity, and the incidence of type 2 diabetes in black and white adults: the atherosclerosis risk in communities study: 19871998. Diabetes Care 2002, 25:1358-1364.

51. Fulkerson JA, French SA: Cigarette smoking for weight loss or control among adolescents: Gender and racial/ethnic differences. J Adolesc Health 2003, 32:306-313.

52. Clark MM, Decker PA, Offord KP, Patten CA, Vickers KS, Croghan IT, TaylorHays T, Hurt RD, Dale LC: Weight concerns among male smokers. Addictive Behaviors 2004, 29:1637-1641.

53. Pisinger $C$, Jorgensen $T$ : Weight concerns and smoking in a general population: the Inter99 study. Preventive Medicine 2007, 44:296-297.

54. Pomerleau CS, Zucker AN, Stewart AJ: Characterizing concerns about postcessation weight gain: results from a national survey of women smokers. Nicotine Tob Res 2001, 3:51-60.

55. Twardella D, Loew M, Rothenbacher D, Stegmaier C, Ziegler H, Brenner H: The impact of body weight on smoking cessation in German adults. Preventive Medicine 2006, 42:109-113.

56. Clair C, Berlin I, Cornuz J: Tabagisme, obésité et diabète: une interaction cliniquement importante. Rev Med Suisse 2011, 7:2338-2342.

doi:10.1186/1617-9625-10-9

Cite this article as: Berlin et al:: Smoking Status and Metabolic Syndrome in the Multi-Ethnic Study of Atherosclerosis. A cross-sectional study. Tobacco Induced Diseases 2012 10:9.

\section{Submit your next manuscript to BioMed Central and take full advantage of:}

- Convenient online submission

- Thorough peer review

- No space constraints or color figure charges

- Immediate publication on acceptance

- Inclusion in PubMed, CAS, Scopus and Google Scholar

- Research which is freely available for redistribution

Submit your manuscript at www.biomedcentral.com/submit 